\title{
Nudging the Arctic Ocean to Quantify Sea Ice Feedbacks
}

\author{
EVELIEN DEKKER \\ Department of Meteorology, and Bolin Centre for Climate Research, Stockholm University, Stockholm, Sweden \\ RICHARD BINTANJA \\ Royal Netherlands Meteorological Institute (KNMI), De Bilt, and Energy and Sustainability Research Institute \\ Groningen, University of Groningen, Groningen, Netherlands \\ CAMIEL SEVERIJNS \\ Royal Netherlands Meteorological Institute (KNMI), De Bilt, Netherlands
}

(Manuscript received 11 June 2018, in final form 28 January 2019)

\begin{abstract}
With Arctic summer sea ice potentially disappearing halfway through this century, the surface albedo and insulating effects of Arctic sea ice will decrease considerably. The ongoing Arctic sea ice retreat also affects the strength of the Planck, lapse rate, cloud, and surface albedo feedbacks together with changes in the heat exchange between the ocean and the atmosphere, but their combined effect on climate sensitivity has not been quantified. This study presents an estimate of all Arctic sea ice related climate feedbacks combined. We use a new method to keep Arctic sea ice at its present-day (PD) distribution under a changing climate in a 50 -yr $\mathrm{CO}_{2}$ doubling simulation, using a fully coupled global climate model (EC-Earth, version 2.3). We nudge the Arctic Ocean to the (monthly dependent) year 2000 mean temperature and minimum salinity fields on a mask representing PD sea ice cover. We are able to preserve about 95\% of the PD mean March and $77 \%$ of the September PD Arctic sea ice extent by applying this method. Using simulations with and without nudging, we estimate the climate response associated with Arctic sea ice changes. The Arctic sea ice feedback globally equals $0.28 \pm 0.15 \mathrm{~W} \mathrm{~m}^{-2} \mathrm{~K}^{-1}$. The total sea ice feedback thus amplifies the climate response for a doubling of $\mathrm{CO}_{2}$, in line with earlier findings. Our estimate of the Arctic sea ice feedback agrees reasonably well with earlier CMIP5 global climate feedback estimates and shows that the Arctic sea ice exerts a considerable effect on the Arctic and global climate sensitivity.
\end{abstract}

\section{Introduction}

The Arctic is one of the regions most affected by climate change (Collins et al. 2013). Observations and modeling studies show that in the Arctic, temperature changes 2-3 times faster than the global mean (Holland and Bitz 2003; Serreze and Barry 2011). This phenomenon, called Arctic amplification, is driven by climate feedbacks, in which sea ice plays a crucial role (Screen and Simmonds 2010). Sea ice is the primary driver of Arctic climate variability and change (van der Linden et al. 2014). Therefore, sea ice related feedbacks constitute a key component of Arctic climate change. With Arctic summer sea ice potentially disappearing

Corresponding author: Evelien Dekker, evelien.dekker@misu. su.se sometime during this century (Snape and Forster 2014), sea ice related climate feedbacks will become substantially weaker once the sea ice vanishes.

The retreat of sea ice induces an albedo feedback as well as an ice-ocean feedback effect, since the removal of the insulating ice layer increases the exchange of heat and moisture between the atmosphere and the ocean (Boisvert et al. 2013; Koyama et al. 2017). The retreat of Arctic sea ice thus modulates the water vapor and cloud feedbacks, and also interacts with the lapse rate feedback by affecting the vertical temperature distribution in the lower atmosphere. The net effect of Arctic sea ice related climate feedbacks is not well known. A negative trend in Arctic sea ice will invoke a cascade of feedback processes in the Arctic that also will have consequences for climate globally. Changes in Arctic sea ice potentially have more widespread impacts on 
climate (Thomas 2014; Overland et al. 2016), such as altering climate extremes in the Northern Hemisphere midlatitudes.

In this paper, "Arctic sea ice feedback" refers to the net change in climate feedbacks at the global scale that is related to changes in Arctic sea ice. This includes local changes in albedo, clouds, and the vertical temperature profile, but also the indirect effects that act on a global scale. Arctic sea ice decline can affect surface heating patterns, as well as the atmospheric pressure distribution. The term Arctic sea ice feedback therefore includes changes in atmospheric heat transport, consequences of changes in the meridional temperature gradient, changing snow cover, and other changes that can be linked to declining Arctic sea ice. All changes in top of the net radiation at the top of the atmosphere (TNR) and surface temperature that are (in)directly associated with a decline in Arctic sea ice as reviewed in Bhatt et al. (2014) constitute our definition of the term Arctic sea ice feedback. Unfortunately, climate feedback parameters are hard to quantify, mainly because feedbacks interact with each other.

The spread of the projected temperature increase north of $70^{\circ} \mathrm{N}$ between 2006 and 2100 is large; CMIP5 models using the RCP8.5 scenario (Collins et al. 2013) project an Arctic temperature increase between $4^{\circ}$ and $13^{\circ} \mathrm{C}$ (Bintanja and Selten 2014). This intermodel spread in projected Arctic changes can be partly linked to differences in the current sea ice state (extent, thickness) in each model (Flato 2004), because a difference in the sea ice state can cause the strength of sea ice feedbacks to vary among the climate models. More importantly, Flato (2004) concluded that intermodel differences in sea ice state and the sea ice response to climate forcing are more driven by feedbacks involving the atmosphere and ocean than by attributes of the sea ice component. Hence, the Arctic sea ice contributes differently to the current climate sensitivity in the various climate models. These considerable differences among climate models concerning the present-day (PD) sea ice state, its variability, and the sea ice feedbacks all contribute to the large spread in future projections of Arctic sea ice and Arctic amplification. In this paper we aim to improve our understanding of climate feedbacks related to the retreat of Arctic sea ice.

Previously, idealized model experiments have been conducted to understand how feedbacks are related to Arctic sea ice and Arctic amplification. For instance, Graversen and Wang (2009) studied the role of the albedo feedback in Arctic amplification and set the surface albedo of sea ice to fixed climatological values so as to separate the effect of a fixed albedo from a freely varying albedo. Further, Graversen et al. (2014) suppressed the lapse rate feedback and the albedo feedback separately. Graversen et al. (2014) found that the lapse rate feedback (15\%) and the surface albedo feedback $(40 \%)$ contributed to Arctic amplification.

The role of sea ice in climate sensitivity has been estimated earlier in slab ocean model experiments (Ingram et al. 1989; Rind et al. 1995, 1997; Caldeira and Cvijanovic 2014). In these studies the effect of both Northern and Southern Hemispheric sea ice retreat in $\mathrm{CO}_{2}$ doubling simulations resulted in a sea ice feedback of $0.18-0.56 \mathrm{~W} \mathrm{~m}^{-2} \mathrm{~K}^{-1}$. Despite their diverging findings, all these studies share the recommendation that future studies should include the coupling with the ocean to capture the effect of sea ice retreat on ocean circulation and heat exchange to better estimate the sea ice feedback. The net effect of Arctic sea ice related climate feedbacks is not fully known, because earlier studies that isolate the sea ice effect on climate sensitivity excluded a fully coupled ocean response.

The role of ocean coupling in the climate response to sea ice loss cannot be neglected in equilibrium, as found by idealized model simulation with fixed sea ice. The full coupling plays a crucial role in spreading the effect of Arctic ice loss across the globe; the ocean coupling enhances the hydrological cycle and leads to a more symmetric warming around the equator with warming at high latitudes in both hemispheres (Deser et al. 2015; Tomas et al. 2016). Moreover, the ocean response to sea ice loss may be realized already within 25 years (Wang et al. 2018). Oudar et al. (2017, hereafter OUD17) used similar methods as Deser et al. (2015, hereafter DES15) to fix sea ice in a coupled model and separated the atmospheric response into a component related to increased greenhouse gases (GHGs) and a component related to ice loss. OUD17 showed that it is the sea ice loss that drives the weakening of the low-level meridional temperature gradient associated with decreasing baroclinicity, whereas the GHG effect is located in the mid-high troposphere.

In our study, we aim to quantify what fraction of the current climate sensitivity is associated with Arctic sea ice retreat in reaction to a doubling of $\mathrm{CO}_{2}$. We therefore separate all climate feedbacks related to Arctic sea ice retreat from those unrelated to Arctic sea ice retreat. Graversen et al. (2014) showed that the lapse rate and surface albedo feedbacks interact strongly with each other at high latitudes, "such they cannot be considered independent feedback mechanisms on a global scale." We compare the climate feedback estimate from a free $2 \mathrm{xCO}_{2}$ simulation to the climate feedback from a fixed sea ice $2 \mathrm{xCO}_{2}$ simulation. From the differences between these two simulations we deduce the (combined) feedbacks associated with Arctic sea retreat, taking into 
account the coupling between ocean and atmosphere. The concept to separate the sea ice feedback is similar to Ingram et al. (1989) and Rind et al. (1995), except that we focus only on Arctic sea ice cover. This study adds novelty to previous studies in two ways: 1 ) it takes into account atmosphere-ocean coupling, and 2) we use a new method to separate the effect of Arctic sea ice on the feedbacks in a fully coupled model.

We introduce a new method to keep the sea ice close to its PD distribution by nudging the ocean below the Arctic sea ice toward PD conditions. We compare our method to fix the sea ice compared to those of DES15 and OUD17. We will compare the feedback estimates resulting from both simulations, from which we infer the magnitude of the Arctic sea ice related feedbacks. This comparison allows us to quantify the part of the response caused by sea ice processes, and thus the overall Arctic sea ice feedback, including surface albedo, insulation, and nonlinear interactions with other feedbacks.

\section{Model and method}

\section{a. Model}

The simulations are carried out using EC-Earth, version 2.3 (v2.3; Hazeleger et al. 2012; Sterl et al. 2012). This is a state-of-the-art, fully coupled global climate model used in CMIP5 (Collins et al. 2013). EC-Earth's atmosphere component is the Integrated Forecast System (IFS) of the European Centre for Medium-Range Weather Forecasts (ECMWF) at T159 spectral resolution with 62 vertical levels. EC-Earth's ocean component is represented by the Nucleus for European Modelling of the Ocean (NEMO; Madec et al. 2008) in the ORCA1 configuration. In this configuration, NEMO uses 42 vertical levels and has a $1^{\circ}$ horizontal resolution. The sea ice component, dynamic-thermodynamic Louvain la Neuve sea ice model, version 2 (LIM2; Fichefet and Maqueda 1997; Bouillon et al. 2009), is incorporated in NEMO. The IFS and NEMO component models are coupled using the OASIS3 module (https://portal.enes.org/oasis/).

\section{b. EC-Earth $v 2.3$ performance in capturing present Arctic sea ice characteristics}

The performance of EC-Earth in capturing PD climate, including the Arctic sea ice characteristics, was studied in Sterl et al. (2012). In EC-Earth v2.3, the seasonal cycle of Arctic sea ice extent (SIE) shows realistic values compared to satellite observations. The winter sea ice extent along the east coast of Greenland is slightly overestimated. The values for mean sea ice thickness in March and September fit well to available estimates, except for an overestimation along the Siberian coast. The mean sea ice transport through Fram Strait is in good agreement with available observations. EC-Earth's global climate sensitivity is close to the mean of reported climate sensitivities of the CMIP5 model ensemble (Collins et al. 2013; van der Linden et al. 2017).

The mean state of Arctic sea ice under preindustrial conditions in 33 CMIP5 models was evaluated in van der Linden (2016), and we can compare EC-Earth to the sea ice characteristics of the other models. Under preindustrial circumstances, in EC-Earth the amplitude of the seasonal cycle in Arctic sea ice is very low compared to other CMIP5 models. Also, the total Arctic sea ice area is quite low compared to other models, whereas the total Arctic sea ice volume is comparatively high. In an experiment where preindustrial conditions are perturbed with a transient $1 \%$ increase of $\mathrm{CO}_{2}$ over 140 years, EC-Earth shows the highest Arctic 10-yr surface air temperature trends of all models. Furthermore, ECEarth exhibits the second largest sea ice volume decrease trend of all participating models.

\section{c. Simulations and initial conditions}

Our study consists of three simulations: one 60-yr control simulation with PD conditions (control), and two 50-yr $\mathrm{CO}_{2}$ doubling simulations; one regular doubling simulation $\left(2 \mathrm{xCO}_{2}\right)$, and one in which the Arctic Ocean is nudged to fix the sea ice (nudged). The simulations start at 1 January 2001, for which the initial conditions are taken from the end of the 500-yr equilibrium PD control simulation from van der Linden et al. (2017). The sea ice volume in our initial year is relatively low $\left(\right.$ maximum $=21000 \mathrm{~km}^{3}$, minimum $=8500 \mathrm{~km}^{3}$ ) compared to the values reported in Sterl et al. (2012), but such values have been recorded in 2014 in the satellite product Pan-Arctic Ice Ocean Modeling and Assimilation System (PIOMAS; Schweiger et al. 2011). We discuss possible implication of a relatively low initial sea ice volume later in the discussion. The GHGs and aerosols are kept fixed as in year 2000. To establish the desired PD Arctic sea ice cycle in the nudged $2 \mathrm{xCO}_{2}$ simulation, we apply nudging in the Arctic Ocean.

\section{d. Nudging method}

We anticipate that sea ice can "survive" under warmer atmospheric conditions if we force the Arctic surface waters to be sufficiently fresh and cold. Therefore, we nudge the Arctic Ocean to a prescribed state obtained from the PD Arctic Ocean in the control simulation by restoring the ocean temperature $T$ and salinity $S$. The restoring term in an arbitrary grid cell amounts to 


$$
\begin{aligned}
& \frac{\partial T}{\partial t}=\cdots-\frac{1}{\tau}\left(T-T_{0}\right), \quad \text { and } \\
& \frac{\partial S}{\partial t}=\cdots-\frac{1}{\tau}\left(S-S_{0}\right) .
\end{aligned}
$$

Here, $\tau$ denotes the time scale of restoring, and $T_{0}$ and $S_{0}$ are the prescribed ocean temperature and salinity fields. We apply the nudging in those ocean columns that contain any sea ice cover in the Northern Hemisphere during the 60-yr PD control simulation, depicted by a monthly varying mask. (The September and March nudge mask extent are shown as stippling in Fig. 3.) We nudge the entire ocean column toward the PD state, to avoid $T$ and $S$ profile discontinuities and unrealistic convection in the vertical. Spurious vertical convection might occur when for instance the nudging is applied in the mixed layer only. In such case, the near-surface density could eventually become higher than the density of the underlying ocean layers.

The combination of applied nudge parameters $\left(\tau, T_{0}\right.$, and $S_{0}$ ) that is used in this study is the result of a rigorous testing procedure. By trying different values of $\tau$ and fields of $T_{0}$ and $S_{0}$, we should obtain a sea ice area (SIA) in the nudged that is similar to the SIA in the control during 10-yr test periods. Moreover, the test phase nudged SIA is required to be larger than the minimum SIA (of a particular year) in the control. We arrive at a restoring time scale $\tau=1 / 20$ day, a temperature field $T_{0}$ that contains the climatological means over a 60 -yr PD period and a salinity field $S_{0}$ that contains the climatological minimums over a $60-\mathrm{yr}$ PD period. These values are resulting from a range of test time scales $\tau=1 / 300-5$ day, the climatological mean $T$ and $S$ fields and conditional salt nudging, in which we only nudge $S$ when it leads to freshening. The choice of the minimum salinity as the $S_{0}$ field was found to be crucial to obtain sufficiently accurate SIA.

The nudging method itself affects the way the climate responds to the $\mathrm{CO}_{2}$ perturbation because the restoring of the Arctic Ocean to a prescribed field yields an extra source or sink of energy in the climate system. We calculate the temperature and salinity tendencies caused by the nudging during model integration [i.e., $-\tau^{-1}\left(T-T_{0}\right)$ and $\left.-\tau^{-1}\left(S-S_{0}\right)\right]$. We keep track of this nudging imposed heat sink during model integration, which is given by

$$
E_{\text {nudge }}=-\frac{1}{A_{\text {earth }}} \iiint \frac{1}{\tau}\left(T-T_{0}\right) C_{p} \rho_{0} d V,
$$

where $A_{\text {earth }}$ is the global area of Earth, $C_{p}$ is the heat capacity of seawater $\left(\mathrm{J} \mathrm{kg}^{-1} \mathrm{~K}^{-1}\right), V$ is the volume of the cell $\left(\mathrm{m}^{3}\right)$, and $\rho_{0}$ is the density of seawater $\left(\mathrm{kg} \mathrm{m}^{-3}\right)$.
Presumably, the application of nudging in the deep Arctic Ocean affects the temperature in the ocean outside the Arctic on longer time scales by advecting the imposed signal of the Arctic basin to lower latitudes. Therefore, we only use 50 years of integration to evaluate the climate feedbacks. These 50 years we use to diagnose the climate feedbacks represent a relatively short time scale for horizontal advection out of the Arctic Ocean basin to occur. The sea surface temperature (SST) response outside the nudged area shows similar patterns as the SST response in the $2 \mathrm{xCO}_{2}$ simulation, and the SST response inside the nudged area is the same as in the control, from which we infer that the effect of Arctic nudging outside the Arctic is comparatively small.

\section{Results}

In this section we show how the nudging technique performs in maintaining PD sea ice characteristics both for annual and seasonal means. We also present how the global mean and Arctic temperature response differs in the nudged versus the $2 \mathrm{xCO}_{2}$ simulation. Arctic sea ice is defined as all sea ice in the Northern Hemisphere. We otherwise define Arctic as the average of all regions poleward of $70^{\circ} \mathrm{N}$. Finally, we will evaluate the sea ice feedback.

\section{a. Global annual average response to a doubling of $\mathrm{CO}_{2}$}

The nudged annual mean sea ice area stays constant, implying that the nudging procedure succeeds in maintaining a sea ice cover that is similar to the control throughout the whole simulation (Fig. 1a). The nudging leads, however, to an immediate drop in Arctic sea ice area compared to the $2 \mathrm{xCO}_{2}$ simulation in the year of initialization. We elaborate on this initialization issue in the discussion. The Arctic sea ice volume (SIV) decreases rapidly in the $2 \mathrm{xCO}_{2}$ simulation (Fig. 1b). In contrast, the nudging allows for the growth of thicker ice than the control in the initial stage of the simulation. This increased initial thickness implies that the prescribed low salinity, and cooler ocean state allows for the growth of thicker ice given the same $\mathrm{PD} \mathrm{CO} 2$ conditions as in the control. The sea ice thins during the first 25 years in both the $2 \mathrm{xCO}_{2}$ and the nudged simulations. After 25 years, the sea ice volume in the nudged and $2 \mathrm{xCO}_{2}$ simulation reaches a quasi-stable state.

The Arctic $T_{2 \mathrm{~m}}$ increases rapidly from $-11^{\circ}$ to $-5^{\circ} \mathrm{C}$ in the free $2 \mathrm{xCO}_{2}$ simulation during the first 25 years, followed by a more gradual increase up to $-4^{\circ} \mathrm{C}$ in the last year. In the nudged simulation, however, the temperature increase in the Arctic is less pronounced; it 
a) Arctic sea ice area (SIA)

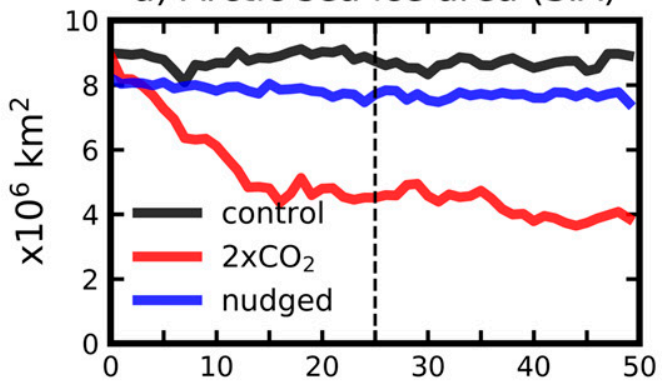

b) Arctic sea ice volume (SIV)

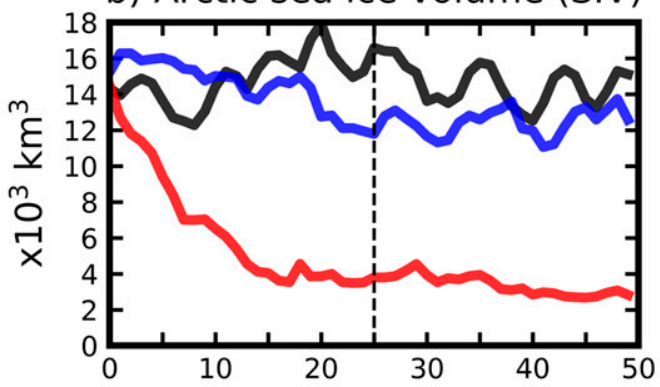

c) Arctic mean $2 m$ temp. $\left(T_{2 m}\right.$, Arctic $)$

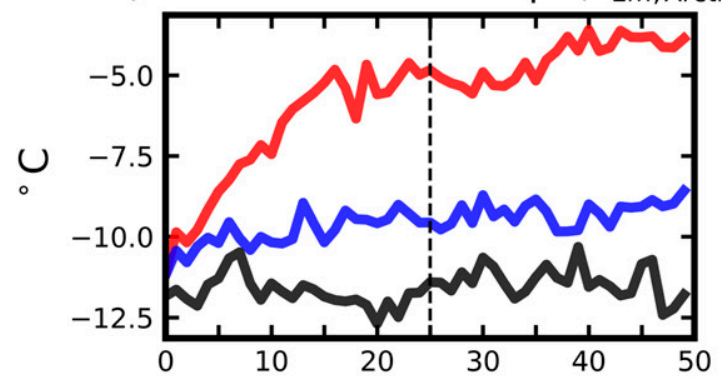

d) Global mean $2 \mathrm{~m}$ temp change $\Delta \mathrm{T}_{2 m}$

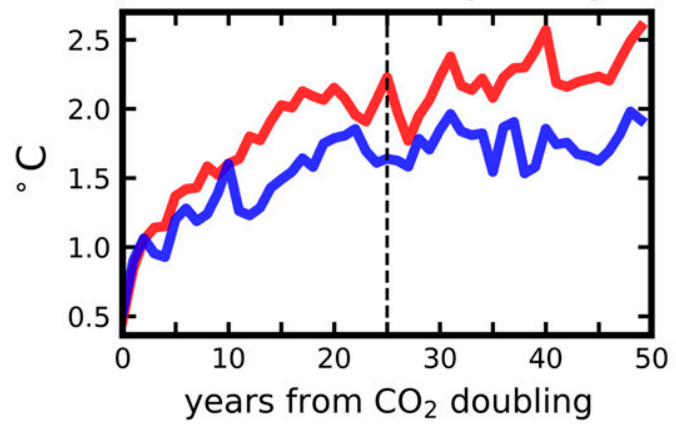

FIG. 1. Annual average response to a doubling of $\mathrm{CO}_{2}$ of several key parameters. Simulations: control (black), nudged (blue), and $2 \mathrm{xCO}_{2}$ (red). (a) Arctic sea ice area in million squared kilometers. (b) Arctic sea ice volume in thousands cubed kilometers. (c) Arctic mean 2-m temperature. (d) Global mean 2-m temperature change, here defined as the annual average of the simulation minus the annual average of the control. The vertical line indicates the year where we decide that the Arctic sea ice volume in the nudged simulation stabilized. The last 25 years are used to compute the annual mean response (Table 1) and seasonal averages (Figs. 2 and 3).
TABLE 1. The annual average in the last 25 years of the simulations. The global mean 2-m temperature $T_{\text {global }}$, the Arctic 2-m temperature $T_{\text {Arctic }}$, and Arctic amplification (AA), Arctic SIA, SIV, and SIE. The standard deviations are calculated for the detrended last 25 years.

\begin{tabular}{llccc}
\hline & Units & Control & Nudged & $2 \mathrm{xCO}_{2}$ \\
\hline$T_{\text {global }}$ & ${ }^{\circ} \mathrm{C}$ & $14.3 \pm 0.1$ & $16.0 \pm 0.1$ & $16.5 \pm 0.1$ \\
$T_{\text {Arctic }}$ & ${ }^{\circ} \mathrm{C}$ & $-11.4 \pm 0.5$ & $-9.3 \pm 0.3$ & $-4.5 \pm 0.3$ \\
AA & Factor & - & 1.3 & 3 \\
SIA & $10^{6} \mathrm{~km}^{2}$ & $8.7 \pm 0.2$ & $7.7 \pm 0.1$ & $4.3 \pm 0.2$ \\
SIE & $10^{6} \mathrm{~km}^{2}$ & $10.2 \pm 0.2$ & $9.2 \pm 0.1$ & $5.4 \pm 0.2$ \\
SIV & $10^{3} \mathrm{~km}^{3}$ & $14.5 \pm 1.1$ & $12.5 \pm 0.7$ & $3.4 \pm 0.3$ \\
\hline
\end{tabular}

increases gradually from $-11^{\circ}$ to $-9^{\circ} \mathrm{C}$ over the 50 years. The global mean $T_{2 \mathrm{~m}}$ increase (Fig. 1d) is similar in the nudged and the $2 \mathrm{xCO}_{2}$ simulations in the first two years. After this initial stage, the nudged simulation exhibits a lower global mean temperature change compared to the $2 \mathrm{xCO}_{2}$, as expected. The application of the nudging method establishes a $0.7^{\circ} \mathrm{C}$ difference in global mean temperature after 50 years of integration compared to the nonnudged $2 \mathrm{xCO}_{2}$ simulation.

The nudged Arctic sea ice and the nudged global mean temperature appear to reach a new annual mean (quasi) equilibrium state after 25 years. Therefore, we use the final 25 years of the integrations to determine the annual and seasonal mean response. Table 1 summarizes some key climate variables averaged over the last 25 years. The Arctic key variables values (SIA, SIV, SIE, and $\left.T_{\text {Arctic }}\right)$ from the nudged simulation are indeed more in accordance with the values from the control than the values from the $2 \mathrm{xCO}_{2}$ simulation. The Arctic amplification is only 1.3 in the nudged simulation compared to 3.1 in the $2 \mathrm{xCO}_{2}$ simulation. The global mean temperature is $0.5^{\circ} \mathrm{C}$ lower in the nudged simulation compared to in the $2 \mathrm{xCO}_{2}$ simulation. Furthermore, the variability of the annual mean SIV as measured by its standard deviation is largest in the control and smallest in the $2 \mathrm{xCO}_{2}$ simulation. The ocean is less variable below the sea ice in the nudged simulation, which could explain the lower SIV variability in the nudged compared to the control simulation. The SIV variability in the $2 \mathrm{xCO} 2$ simulation is small, but nonetheless a large fraction of the total signal, because the summer sea ice disappeared in the $2 \mathrm{xCO}_{2}$ simulation.

\section{b. Arctic seasonal response}

The Arctic is a region with strong seasonality; therefore, annual averages are not sufficient to assess the performance of the nudging procedure to maintain sea ice. The seasonal cycle of Arctic temperature is quite well reproduced during the period of sea ice melt (March-August), where the nudging performed well in maintaining the length of the period of sea ice melt 

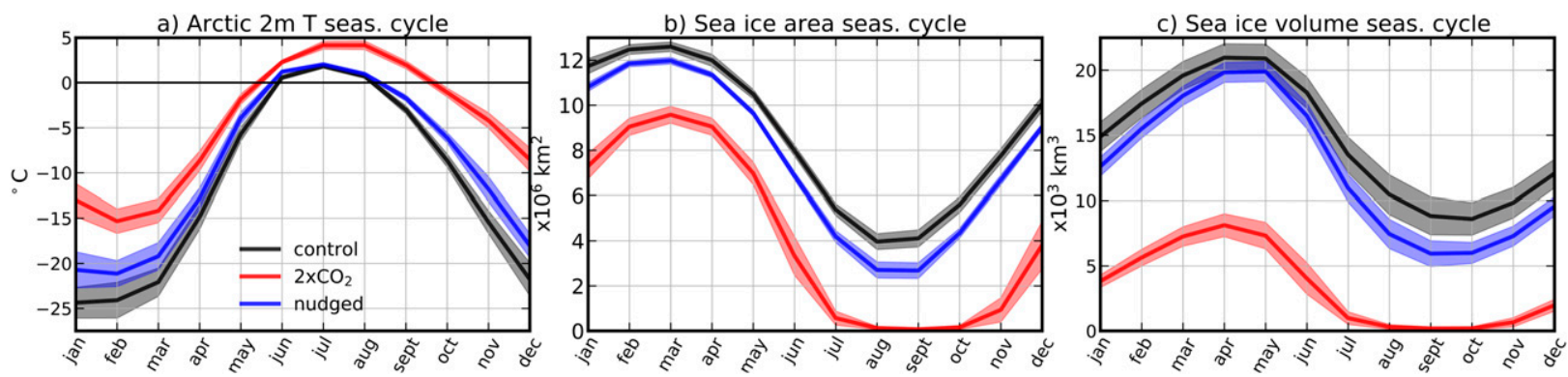

FIG. 2. The seasonal cycle computed as the climatological mean from the last 25 years of integration. Simulations: control (black), nudged (blue), and $2 \mathrm{xCO}_{2}$ (red). (a) Arctic 2-m temperature, (b) Arctic sea ice area in million squared kilometers, and (c) Arctic sea ice volume in thousands cubed kilometers. The band corresponds to one standard deviation of the 25 -yr sample.

(around $0^{\circ} \mathrm{C}$ ) in the Arctic equally long as in the control (Fig. 2a). In the winter months, the temperature difference between the control and the other simulations is the largest. In the $2 \mathrm{xCO}_{2}$ simulation the length of the period above freezing is two months longer, and winter temperatures are more than $10^{\circ} \mathrm{C}$ higher. The seasonal cycle of SIA is well reproduced with an almost constant offset during the entire winter (Fig. 2b). The nudged sea ice volume agrees well from October until June but less so in summer (Fig. 2c). The $2 \mathrm{xCO}_{2}$ is losing summer sea ice volume as expected.
Figure 3 shows climatological mean sea ice thickness maps with the sea ice edge of the control average shown in gray. The sea ice extent as a fraction of the control extent (shown in percentages) in the nudged simulation is similar to that of the control, both in winter and in summer. The sea ice extent in the nudged simulation matches the extent of control well. Sea ice thickness in the central Arctic decreases by $0.5 \mathrm{~m}$ in the nudged simulation compared to the control but is conserved relatively well when compared to the much thinner sea ice in the $2 \mathrm{xCO}_{2}$ simulation.
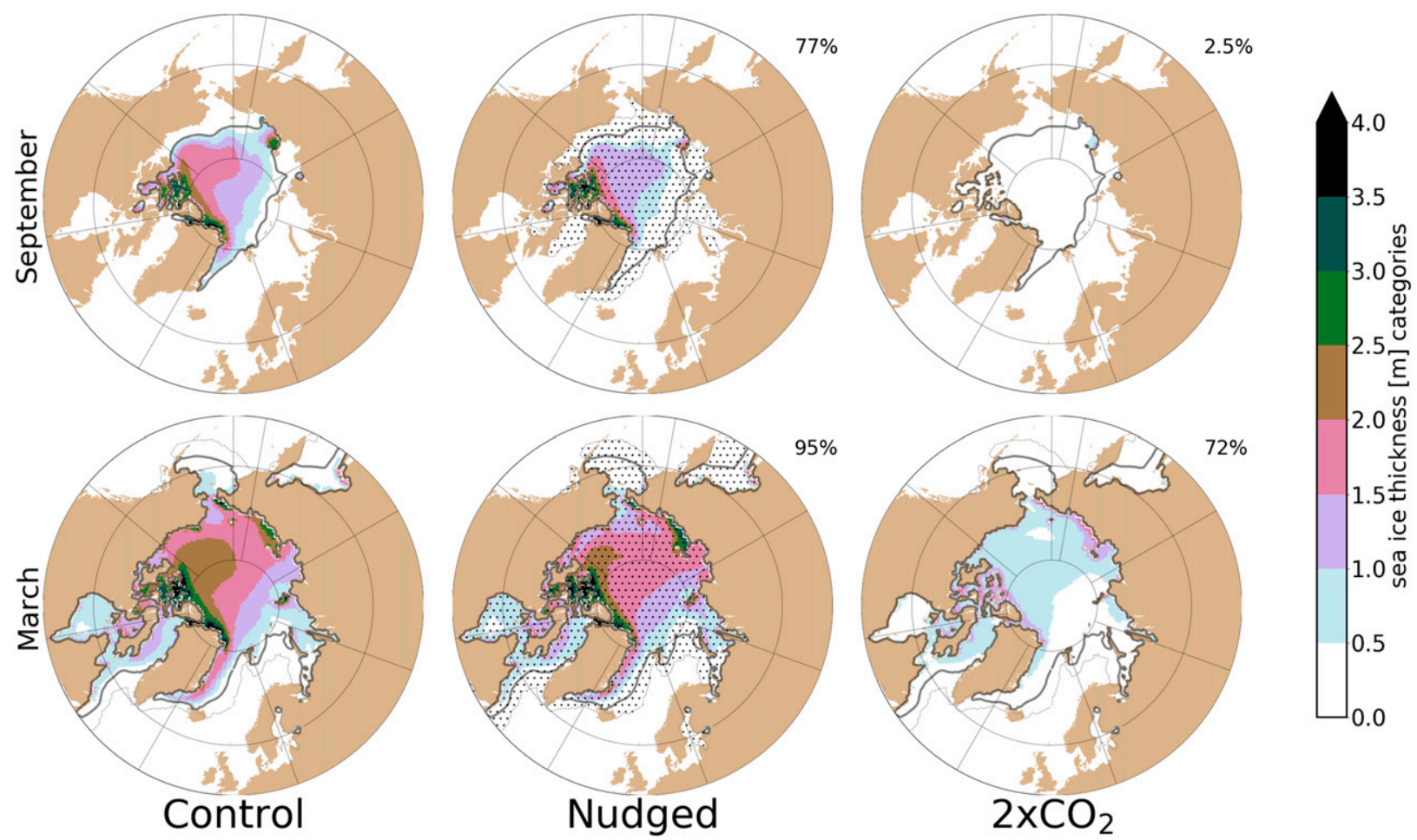

FIG. 3. Climatological mean sea ice thickness in the last 25 years of integration for (top) September and (bottom) March. The gray line represents the mean position of the sea ice edge in 2026-2050 in the control; the contour is $15 \%$ sea ice concentration. The stippling indicates the extent of the nudge mask. The percentages indicate the mean fraction of control sea ice extent that is restored by the nudging. 
In contrast to the $2 \mathrm{xCO}_{2}$ simulation, no sea ice retreat occurs in the Barents Sea in the nudged simulations. This result supports the general view that the ocean plays a key role in the sea ice retreat in the Barents Sea (Årthun et al. 2012; Smedsrud et al. 2013; Li et al. 2017), because by specifically nudging the ocean, sea ice is preserved there. This is in line with findings from earlier studies, in which it was found that the Barents Sea is a dominant region for total Arctic sea ice variability and that the ocean heat transport is the dominant contributor to sea ice retreat in the Barents Sea (van der Linden et al. 2017).

\section{c. Sea ice feedbacks}

We conclude that the nudging results in a sea ice distribution that is reasonably close to the control sea ice extent (77\% in September and 95\% in March). The areal extent and volume agree much better with the control than with the $2 \mathrm{xCO}_{2}$ simulation. Even though the nudging procedure is not perfect, we can use these simulations to quantify the climate feedback strength associated with the retreat of Arctic sea ice, referred to as the sea ice feedback $\lambda_{\text {ice }}$.

\section{1) Conceptual approach to separate the SEA ICE FEEDBACK FROM THE CLIMATE FEEDBACK}

Classically, in climate feedback studies the climate feedback parameter $\lambda_{f}$ is decomposed in several feedbacks such as the Planck feedback $\lambda_{0}$, the lapse rate $\lambda_{\Gamma}$, the water vapor $\lambda_{\mathrm{WV}}$, the cloud $\lambda_{c}$, and the albedo $\lambda_{\alpha}$ : $\lambda_{f}=\sum_{i} \lambda_{i}=\lambda_{0}+\lambda_{\Gamma}+\lambda_{W V}+\lambda_{c}+\lambda_{\alpha} \quad$ (Goosse et al. 2010; Mauritsen et al. 2013). This decomposition implies that each feedback process is independent of others, even though it has been shown that this assumption does not quite hold in the Arctic region (Graversen et al. 2014). We aim to quantify the Arctic sea ice feedback including the nonlinear dependencies between $\lambda_{0}, \lambda_{\Gamma}, \lambda_{w}, \lambda_{c}$, and $\lambda_{\alpha}$. To this end, we assume that the differences in the atmospheric circulation and feedbacks between the $2 \mathrm{xCO}_{2}$ and the nudged simulation are entirely associated with the retreat of Arctic sea ice. Therefore, we compute the climate feedback strengths in the $2 \mathrm{xCO}_{2} \lambda_{f}^{2 \mathrm{xCO}_{2}}$ and the nudged simulation $\lambda_{f}^{\text {nudged }}$, and we subsequently assume the difference between these two to be caused only by sea ice related feedbacks. Consequently, we subtract $\lambda_{f}^{2 \mathrm{xCO}_{2}}$ from $\lambda_{f}^{\text {nudged }}$, thereby separating the feedbacks related to Arctic sea ice and unrelated to sea ice:

$$
\lambda_{\text {ice }}=\lambda_{f}^{2 \mathrm{xCO}_{2}}-\lambda_{f}^{\text {nudged }} .
$$
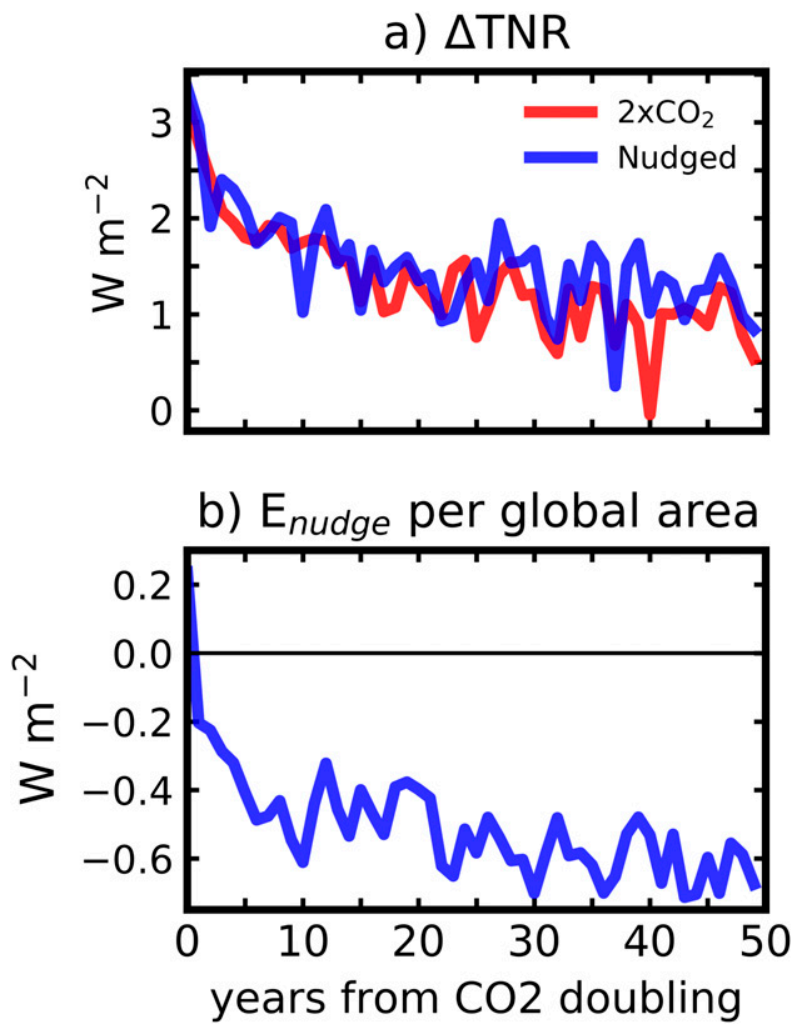

FIG. 4. (a) Global annual means of net radiation change TOA compared to control (simulation control). (b) Global annual means of nudge energy, all temperature tendencies from the nudging procedure from Eq. (1) converted to heat [Eq. (3)]. Negative $E_{\text {nudge }}$ indicates heat loss.

\section{2) QUANTIFY THE SEA ICE FEEDBACK}

To quantify the climate feedbacks in each 50 -yr simulation, we follow the procedure of Gregory et al. (2004). In this method, TNR (see Fig. 4a) is regressed against the global mean 2-m temperature change $\Delta T_{2 \mathrm{~m}}$ (Fig. 1d). From this regression line we obtain the equilibrium temperature change $\Delta T_{\text {eq }}$ when TNR is zero and the initial forcing $\Delta Q\left(\mathrm{~W} \mathrm{~m}^{-2}\right)$ when $\Delta T_{2 \mathrm{~m}}$ is zero. The feedback is calculated as $\lambda_{f}=-\Delta Q / \Delta T_{\text {eq }}$, which is the slope of the regression line. The resulting statistics of these regressions (Fig. 5) are shown in Table 2. The sea ice feedback strength estimated by the standard Gregory method is $0.28 \pm 0.15 \mathrm{~W} \mathrm{~m}^{-2} \mathrm{~K}^{-1}$.

The climate feedback framework takes TNR as the net energy flux entering the system. However, in the nudged simulation, the nudging itself imposes an extra energy flux in the system. Therefore, we also discuss an alternative method to diagnose the climate feedback from the nudged simulation in the appendix. In this alternative method, we take into account all energy used in the nudging $E_{\text {nudge }}$ [see Eq. (3)] as an external forcing 


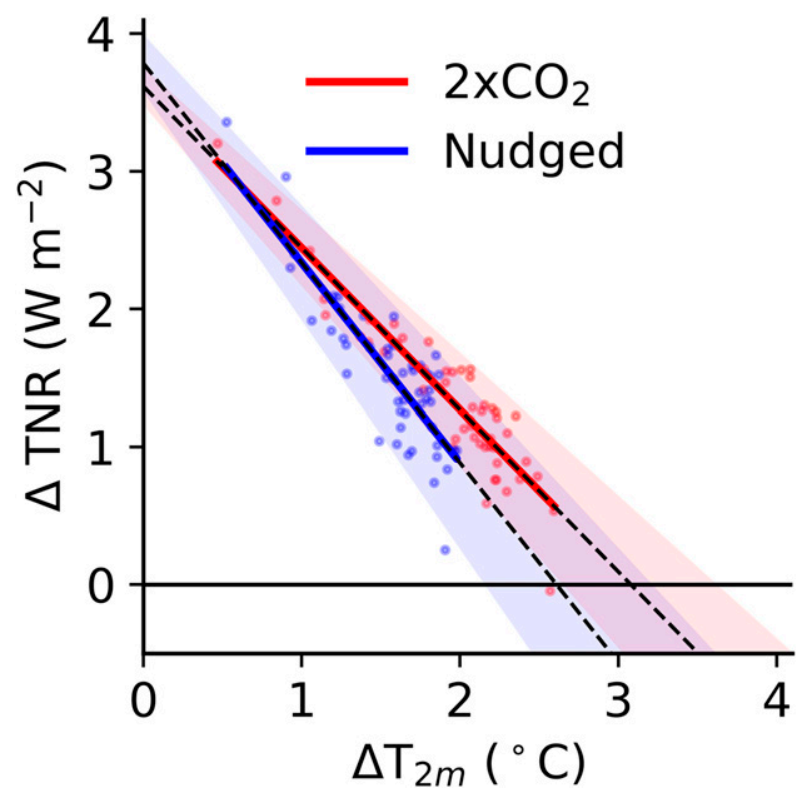

FIG. 5. Regression line to obtain the climate feedback estimate as by Gregory et al. (2004). Simulations: nudged (blue) and $2 \mathrm{xCO}_{2}$ (red). The scatter shows annual averages of fifty years. The line shows the linear regression through these points. The contours show the band of error from the slope error and the intercept error. Corresponding slope statistics are shown in Table 2. Regression where the top radiation change at the top of the atmosphere difference $\Delta \mathrm{TNR}$ with the control is regressed against the global mean 2-m temperature change $\Delta T_{2 \mathrm{~m}}$.

of the climate system. We focus on the result obtained following the standard Gregory method; a discussion about the result from the alternative method can be found in the appendix.

We put the estimated Arctic sea ice feedback range of $0.28 \pm 0.15 \mathrm{~W} \mathrm{~m}^{-2} \mathrm{~K}^{-1}$ in context with results from other studies that evaluated Arctic feedbacks. First, we compare our findings to the climate feedback parameters found in instantaneous $2 \mathrm{xCO}_{2}$ forced experiments from CMIP5 simulations (Collins et al. 2013), summarized in Table 3. We expect the sea ice feedback to be positive because all previous studies have shown that both the lapse rate and the albedo feedbacks amplify the climate response in the Arctic (Graversen and Wang 2009; Block and Mauritsen 2013). OUD17 separated the sea ice loss effects on the atmosphere from the effect of increased GHG. They found that Arctic sea ice loss, and not GHGs, leads to a warming that is more strongly confined to the surface in the Arctic. Therefore, we expect positive contribution from the lapse rate feedback.

Our estimate of $0.28 \pm 0.15 \mathrm{~W} \mathrm{~m}^{-2} \mathrm{~K}^{-1}$ falls reasonably well in the range of earlier estimates of the global sea ice temperature feedback related to albedo evaluated by Bintanja and Oerlemans (1995) $\left(0.53 \mathrm{~W} \mathrm{~m}^{-2} \mathrm{~K}^{-1}\right)$, whose result reflects the albedo feedback strength related to changes in sea ice area in both the Arctic and the Antarctic.

The role of global sea ice in $2 \mathrm{xCO}_{2}$ sensitivity was constrained in three others studies with slab ocean models (Table 4). Our result of $0.28 \mathrm{~W} \mathrm{~m}^{-2} \mathrm{~K}^{-1}$ is within this range of global sea ice feedback estimates that besides albedo, also includes changes in clouds, water vapor and lapse rate. In contrast to the sea ice feedbacks in Table 4, we only consider the influence of sea ice in one hemisphere. If one would expect each pole to contribute half of the sea ice feedback, $0.28 \mathrm{~W} \mathrm{~m}^{-2} \mathrm{~K}^{-1}$ might seem quite high compared to results from Ingram et al. (1989) and Caldeira and Cvijanovic (2014). We know, however, from observations that the Arctic sea ice cover responds much stronger to current climate changes than the Antarctic sea ice cover.

In general, different models and experiment designs lead to different results, but apart from those, there are several reasons why our estimate could be relatively high compared to the other estimates in Table 4. Our model resolves physical processes at much higher resolution than the values reported below, which could influence how strongly the feedbacks (mainly cloud feedback) are represented. Further, the Arctic sea ice cover in EC-Earth is quite sensitive relative to other CMIP5 models, because the EC-Earth temperature trend in the Arctic is relatively high after 150 years of $1 \% \mathrm{CO}_{2}$ increase, while EC-Earth started with the thickest initial sea ice (van der Linden et al. 2014). Furthermore, the coupling between the ocean and atmosphere itself can lead to higher global mean temperature (DES15). In addition, our initial sea ice volume is relatively low; the influence on our results is addressed in the discussion. The result from our experiment falls reasonably within the framework of sea feedbacks provided by earlier studies.

TABLE 2. Slope estimation using the method of Gregory et al. (2004). The uncertainties of the slope and the intercept obtained from least squares fit, where the line is fit by minimizing the residuals only in $y$.

\begin{tabular}{lccccr}
\hline \hline Simulation & Slope $\lambda_{f}$ & Intercept $\Delta Q$ & $\Delta T_{\text {eq }}$ & $r$ & $p$ \\
\hline $2 \mathrm{xCO}_{2}$ & $-1.17 \pm 0.07$ & $3.62 \pm 0.14$ & 3.08 & 0.93 & $8.19 \times 10^{-22}$ \\
Nudged & $-1.45 \pm 0.13$ & $3.79 \pm 0.21$ & 2.61 & 0.85 & $8.37 \times 10^{-15}$ \\
\hline
\end{tabular}


TABLE 3. Climate feedback strengths $\left(\mathrm{W} \mathrm{m}^{-2} \mathrm{~K}^{-1}\right.$ ) from CMIP5 models from $\mathrm{CO}_{2}$ doubling experiments, adapted from Table 9.5 in Collins et al. (2013). The multimodel mean climate feedback parameter from 23 models obtained using Gregory et al. (2004). The multimodel mean strengths of the individual feedbacks from 9 models in Vial et al. (2013), using the radiative kernel method from Soden et al. (2008). EC-Earth v2.3 is not included in the ensemble. The $\lambda_{\text {ice }}$ from this study is in the right column.

\begin{tabular}{lcccccrr}
\hline \hline & $\lambda_{\text {total }}$ & $\lambda_{\text {Planck }}$ & $\lambda_{\mathrm{WV}}$ & $\lambda_{\Gamma}$ & $\lambda_{\alpha}$ & $\lambda_{\text {cloud }}$ & $\lambda_{\text {ice }}$ \\
\hline Model mean & -1.1 & -3.2 & 1.6 & -0.6 & 0.3 & 0.3 & $0.28 \pm 0.15$ \\
$90 \%$ uncertainty & \pm 0.5 & \pm 0.1 & \pm 0.3 & \pm 0.4 & \pm 0.1 & \pm 0.7 & - \\
\hline
\end{tabular}

\section{Discussion}

We have shown that by nudging the Arctic Ocean under the sea ice we can "fix" sea ice in a $\mathrm{CO}_{2}$-perturbed coupled model simulation. First, we compare our nudging method to earlier studies in which Arctic sea ice is "fixed" and discuss some limitations of our method. Using the Gregory method, we have estimated $\lambda_{\text {ice }}$ to be $0.28 \pm 0.15 \mathrm{~W} \mathrm{~m}^{-2} \mathrm{~K}^{-1}$. In the second part of the discussion, we address how this result could depend on the initial sea ice condition, and provide some avenues for further research.

\section{a. Comparison of nudging the Arctic Ocean to other methods to constrain sea ice}

To quantify the role that sea ice plays in a climate response to a perturbation, a comparison between model experiments containing normal and fixed sea ice is required. Such experiments include unphysical treatment of the model components that influence sea ice. Several modeling protocols have been applied to obtain a desired sea ice state in coupled ocean-atmosphere models. We compare our approach — nudging the ocean componentto methods that influence to sea ice model directly.

Our method to fix Arctic sea ice is compared to the methods of DES15 and OUD17, whose approaches are similar. The experimental design of DES15 and OUD17 aims to obtain a late twentieth-century and a late twenty-first-century sea ice extent under fixed GHG conditions (Table 5). To realize the sea ice target states, DES15 prescribes additional longwave radiative fluxes to the ice, depending on the climatological sea ice presence in the sea ice target period. OUD17 extended this method by correcting the nonsolar heat flux of the ocean model. Both DES15 and OUD17 prescribed longwave radiative fluxes but, additionally, OUD17 corrects the sensible and latent heat fluxes as "seen" by the sea ice model." To obtain late twenty-first-century sea ice comparable to PD sea ice in their simulations, DES15 apply annually averaged $0.43 \mathrm{~W} \mathrm{~m}^{-2}$ downward longwave radiation to the Arctic sea ice in the CCSM4 model. Their longwave correction flux is seasonally but not spatially varying. OUD17 maintain 1970-2000 averaged Arctic sea ice in a simulation under RCP8.5 2085 radiative forcing. They use heat flux corrections in the nonsolar heat flux to the ocean model (NEMO), specifically applied to model grid cells where $>10 \%$ sea ice retreat occurs between the PD state and the RCP8.5 state.

The main difference between the methods by OUD17 and DES15 and the methodology applied in this paper is that OUD17 and DES15 specifically anticipate the amount of energy required to maintain sea ice (Table 5). In OUD17, the amount of energy required to melt Arctic sea ice into the RCP8.5 state starting from a PD climate is smaller than the energy required to maintain PD Arctic sea ice in a warm RCP8.5 climate. OUD17 also emphasize that the

TABLE 4. Global sea ice feedback estimates from earlier $\mathrm{CO}_{2}$ doubling experiments. The first four rows show feedback estimates obtained from slab ocean models in which a normal sea ice component was used to obtain the climate feedback $\lambda_{\text {active }}$ and a fixed sea ice component $\lambda_{\text {fixed }}$. Each study used a different protocol to fix the global sea ice; "presc." refers to prescribing a climatology of sea ice fields (area and thickness). Different methods were used to evaluate the feedback and climate sensitivity. "Equil." refers to subtracting the equilibrium temperature of the control from the equilibrated $2 \mathrm{xCO}_{2}$ experiment The last row shows our study, which only fixed the Arctic sea ice. We compare the numbers of the last column.

\begin{tabular}{|c|c|c|c|c|c|c|}
\hline Study & Model & Experimental design sea ice & Method & $\lambda_{\text {active }}$ & $\lambda_{\text {fixed }}$ & $\lambda_{\text {ice }}$ \\
\hline Ingram et al. (1989) & UKMO 11-lvl GCM & Presc. model climate & Equil. & 0.77 & 0.95 & 0.18 \\
\hline Rind et al. (1995) & GISS GCM & Presc. from observations & Equil. & 0.95 & 1.51 & 0.56 \\
\hline Caldeira and Cvijanovic (2014) & CESM 1.0.4 & No sea ice, SST below freezing & Gregory & 1.10 & 1.32 & $0.22 \pm 0.10$ \\
\hline Caldeira and Cvijanovic (2014) & CESM 1.0.4 & $\begin{array}{l}\text { Presc. extent model climate, fixed } \\
\text { thickness }(1 \mathrm{~m})\end{array}$ & Gregory & 1.10 & 1.31 & $0.21 \pm 0.19$ \\
\hline This study, NH ice only & EC-Earth v2.3 & Nudge Arctic Ocean & Gregory & 1.17 & 1.45 & $0.28 \pm 0.15$ \\
\hline
\end{tabular}


TABLE 5. Heat flux correction term $\left(\mathrm{W} \mathrm{m}^{-2}\right.$ ) (global mean) to maintain the sea ice target under different radiative forcing in different studies. DES15 reported annual mean values, and OUD17 reported values from selected months. OUD17 and DES15 use the RCP8.5 scenario for future years and the historical scenario for the 1990 s. For this study, monthly means of $E_{\text {nudge }}$ from the last 25 years are shown. Note that the atmospheres in the simulations of OUD17 and DES15 are in equilibrium with the sea ice target, whereas the atmosphere in our nudged simulation is in transient response the sea ice target.

\begin{tabular}{|c|c|c|c|c|c|c|c|c|c|}
\hline Simulation & Model & SI target & RF & Corrective flux & Annual & January & April & August & October \\
\hline ICE20 (OUD17) & CNRM-CM5 & 1970-99 & 2085 & LW + turbulent & - & -1.56 & -0.61 & -0.14 & -0.79 \\
\hline ICE21 (OUD17) & CNRM-CM5 & 2070-99 & 1985 & $\mathrm{LW}+$ turbulent & - & 1.3 & 0.51 & 0.11 & 0.66 \\
\hline $\begin{array}{l}\text { ICE_coupled_20 } \\
\text { (DES15) }\end{array}$ & CCSM4 & 1980-99 & 2000 & LW & -0.10 & - & - & - & - \\
\hline $\begin{array}{l}\text { ICE_coupled_21 } \\
\text { (DES15) }\end{array}$ & CCSM4 & 2080-99 & 2000 & LW & 0.43 & - & - & - & - \\
\hline Nudged (this study) & EC-Earth v2.3 & 2000 & $2 \mathrm{xPD} \mathrm{CO}_{2}$ & Nudge $T, S$ Arctic Ocean & -0.59 & -0.47 & -0.49 & -0.9 & -0.6 \\
\hline
\end{tabular}

difference in required energy required is related to the strong local feedbacks associated with the retreat of sea ice. In contrast to our method, the methodology of DES15 and OUD17 applies the smallest energy correction in summer, and the largest in winter. This contrast is expected because the Arctic amplification is strongest in winter.

A thorough comparison between the various methods is hampered by the use of different models, with different GHG scenarios and different sea ice targets. The seasonal cycle of SIA and SIV (Figs. 2b,c) is reasonably close to our target PD sea ice state. The methods of DES15 and OUD17 result in a better match with their target sea ice extent in summer, but overestimate the volume in winter. All methods do not conserve energy (Table 5), but the advantage of our ocean nudging method is that a smaller energy correction is required to obtain the target sea ice state. We show the maximum effect that $E_{\text {nudge }}$ can have on our estimate in the appendix. In DES15 and OUD17, the energy correction is a prescribed climatology, whereas our energy correction depends on the ocean field during model integration.

This difference is inherent to different aims in the respective studies: DES15 and OUD17 assess the resulting climate response after an abrupt ice loss, whereas our method aims to maintain the current sea ice state while the rest of the climate is responding. DES15 and OUD17 only study the mean equilibrium response; hence OUD17 and DES15 do not need to vary the energy increments associated with the desired sea ice state from year to year. In contrast, we aim to study the transient response. This gives rise to a few disadvantages of our method: we have a state-dependent energy correction flux; our method has an initialization issue with the ocean; we do not conserve salt in the ocean, and therefore we do not know the effect of salt loss on our sea ice feedback result. Such complicating issues hinder the interpretation of results obtained by idealized model experiments in which nudging is applied, but do provide useful results on the effect of sea ice decline on the climate response.

An important issue with respect to our nudging method is that Arctic sea ice extent in the control simulation is not exactly similar to the Arctic sea ice extent in the nudged simulation. The largest mismatch in sea ice cover between the nudged and the control simulation occurs in late summer and early autumn. This mismatch may influence the accuracy of our approach in quantifying the effects of sea ice related feedbacks. However, we argue that the error in our estimate of the Arctic sea ice feedback due to the mismatch of sea ice extent is relatively small.

The nudging procedure neutralizes the sea ice albedo effect by removing energy that would otherwise melt sea ice or prevent sea ice formation later in the season. Hence, shortwave radiation (SW) penetrating open water in the mismatch area will not effectively warm the ocean in the nudged simulation. This would imply that a fraction of $E_{\text {nudge }}$ is not just an artificial heat sink but imitates the effect of sea ice on SW radiation over areas where the nudging is not able to form sea ice. Thus, the sea ice albedo feedback will be largely ineffective even over those regions where the sea cover loss occurs in the nudged experiment. Therefore, we argue that our nudging simulation will capture the majority of the total sea ice feedback.

\section{b. Sensitivity to initial sea ice volume}

The initial sea ice volume of the experiment could influence the resulting temperature increase in climate change experiments. In model simulations with a thinner control sea ice cover, the total sea ice extent decrease is larger (Rind et al. 1995; Holland and Bitz 2003), presumably because a thinner ice cover is more sensitive to lose area than a thicker ice cover. Flato (2004) found that CMIP2 models that produce thick ice in their control integration exhibit less warming than those with thin ice. Andry et al. (2017) found that the albedo 
feedback is strongest when the mean spring sea ice thickness north of $70^{\circ}$ reaches a thickness of $0.5 \mathrm{~m}$, which is not the case in our $2 \mathrm{xCO}_{2}$ experiment. How fast this threshold is reached might change depending on the initial sea ice thickness. This implies that the strength of the albedo feedback could depend upon our initial sea ice volume. Given these summarized findings, we could expect our result to represent a sensitive sea ice case, because we initialize our experiment with a relatively low Arctic sea ice volume. This implies that our reported sea ice feedback might be higher than it would have been in a case with more the initial sea ice volume.

Several other studies imply that the initial sea ice conditions should not matter much for the final realized temperature in $\mathrm{CO}_{2}$ increase scenarios. Tietsche et al. (2011) completely removed Arctic sea ice several times during an increased $\mathrm{CO}_{2}$ emission scenario and found that the sea ice cover grew back after the complete removal within a few years. They argue that their result implies that small errors in sea ice initial conditions should not significantly affect the final warming in climate change scenarios, because the intrinsic memory of Arctic sea ice seems to span only a few years. Furthermore, van der Linden et al. (2014) found that the CMIP5 intermodel spread in the Arctic mean temperature trend after 140 years of $1 \% \mathrm{yr}^{-1} \mathrm{CO}_{2}$ increase is only weakly to related to the initial Arctic sea ice volume. The warming response to a $\mathrm{CO}_{2}$ increase is not uniformly related to the sea ice response to a $\mathrm{CO}_{2}$ increase (Flato 2004), making it difficult to assess what the effect of different sea ice initial conditions is on the Arctic sea ice feedback strength.

Thus, the importance of initial sea ice volume for Arctic sea ice feedbacks is not very well established. Additionally, the initial condition influence on the Arctic sea ice feedback is not only sensitive to the initial Arctic sea ice state, because initial conditions are also closely connected to the corresponding oceanic and atmospheric forcing regimes in the initialization period. A dedicated sensitivity study including different initial Arctic climate conditions should shed more light on the initial condition dependency of the Arctic sea ice feedback; however, such an experiment is not within the scope of this study. We argue that our estimate of $0.28 \mathrm{~W} \mathrm{~m}^{-2} \mathrm{~K}^{-1}$ probably represents an upper limit of the Arctic sea ice feedback in EC-Earth v2.3.

\section{c. Sensitivity to sea ice model version}

A final point of consideration is the influence of model version. Our simulations were performed with an EC-Earth version using the older sea ice model LIM2 instead of LIM3. The main difference is the more detailed multicategory ice thickness distribution in LIM3 compared to LIM2. Massonnet et al. (2011) show that using LIM3 instead of LIM2 results in an enhanced seasonal and interannual variability of the sea ice extent and a great improvement regarding the simulation of the recent observed Arctic summer sea ice retreat. Because LIM3 is more responsive to changes in atmospheric forcing than LIM2, we might expect the sensitivity of Arctic sea ice to a doubling of $\mathrm{CO}_{2}$ to be larger in the next model version.

\section{d. Future outlook: Constraining uncertainty of $\lambda_{\text {ice }}$}

This study provides an estimate of the Arctic sea ice feedback in a fully coupled climate model. We cannot generalize our estimate of $\lambda_{\text {ice }}$ because it is based on only a single simulation using one model. There could be a number of possible reasons behind the relatively large $\lambda_{\text {ice }}$ resulting from our experiment. It could be a consequence of the atmosphere-ocean coupling itself, it could be caused by the fact that our initial sea ice cover is relatively thin, or it could be related to the model formulation of EC-Earth. This paper shows the potential of the nudging method to be used in a fully coupled model, and we encourage further studies with other fully coupled models to study the Arctic sea ice related feedbacks. Future lines of research could focus on estimating the uncertainty related to several aspects: more ensemble members, model version, and initial sea ice thickness but also on the details of the nudging method. If the protocols to fix sea ice presented in DES15, OUD17, and Screen et al. (2018) are applicable to study processes in transient simulations, it would be interesting to see how dependent the Arctic sea ice feedback is to energy increments related to specific sea ice fixing protocols.

\section{Conclusions}

To quantify the climate feedbacks associated with sea ice retreat, we compared the climate feedback of instantaneously $\mathrm{CO}_{2}$-perturbed simulations starting from present day (PD) to the climate feedback obtained from similar perturbed simulations, in which the Arctic sea ice was artificially kept close to its PD distribution. To this end, we used a nudging procedure in the ocean module (NEMO) of EC-Earth v2.3 and nudged the Arctic Ocean into its PD mean temperature and PD minimum salinity below the PD Arctic sea ice cover. We applied the new nudging method to an instantaneously forced $2 \mathrm{xCO}_{2}$ simulation of 50 years. Through nudging about $95 \%$ PD mean March and $77 \%$ of the mean PD September sea ice extent in the last 25 years was maintained. 

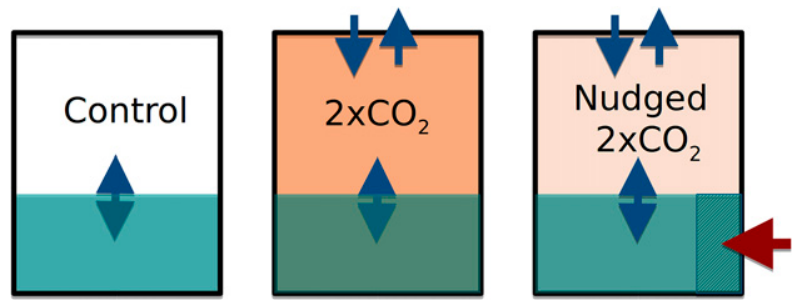

FIG. A1. Conceptual energy fluxes in the climate system of each simulation. The box denotes the climate system. The arrows at the top are the top of the atmosphere net radiation. The control is an equilibrium climate, so the TNR change is zero. The red arrow indicates how $E_{\text {nudge }}$ is interpreted in method B to estimate $\lambda_{\text {ice, } \mathrm{B}}$. The red arrow is defined as positive inwards; the nudge energy is considered as an external forcing of the climate system where positive means an addition of heat and negative means a loss of heat in the nudged area.

We estimated the Arctic sea ice feedback strength by subtracting the climate feedback estimate of the nudged simulation without sea ice retreat from the estimate of the $2 \mathrm{xCO}_{2}$ simulations' climate feedback. Our estimate of the Arctic sea ice feedback equals $0.28 \pm 0.15 \mathrm{~W} \mathrm{~m}^{-2} \mathrm{~K}^{-1}$, in which we used the Gregory method to estimate climate sensitivity. Whether the heat sink in the Arctic Ocean as imposed by the nudging should be taken into account to calculate the Arctic sea ice feedback remains a matter of interpretation. The estimate $0.28 \mathrm{~W} \mathrm{~m}^{-2} \mathrm{~K}^{-1}$ represents all changes in top of the atmosphere net radiation and surface temperature that are (in)directly related to a decline in Arctic sea ice, both locally and globally. This estimate of Arctic sea ice feedback compares reasonably well with earlier CMIP5 global climate feedback estimates and shows that the Arctic sea ice amplifies to a considerable extent the global climate response.

Acknowledgments. ED acknowledges support from the Knut and Alice Wallenberg Foundation (KAW 2016.0024). Most work was carried out at KNMI, funded by KNMI. Comments by Gunilla Svensson and Johan Nilsson were essential for improving this article. In addition, we thank Frank Selten, Eveline van der Linden, and the EC-Earth consortium for their support. The productive and supportive discussions with Rune Graversen and Hildred Crill are gratefully acknowledged. We thank the reviewers for their comments that improved the paper.

\section{APPENDIX}

\section{Methods to Compute the Sea Ice Feedback}

We present as our main result the climate feedback parameter by applying the standard Gregory method
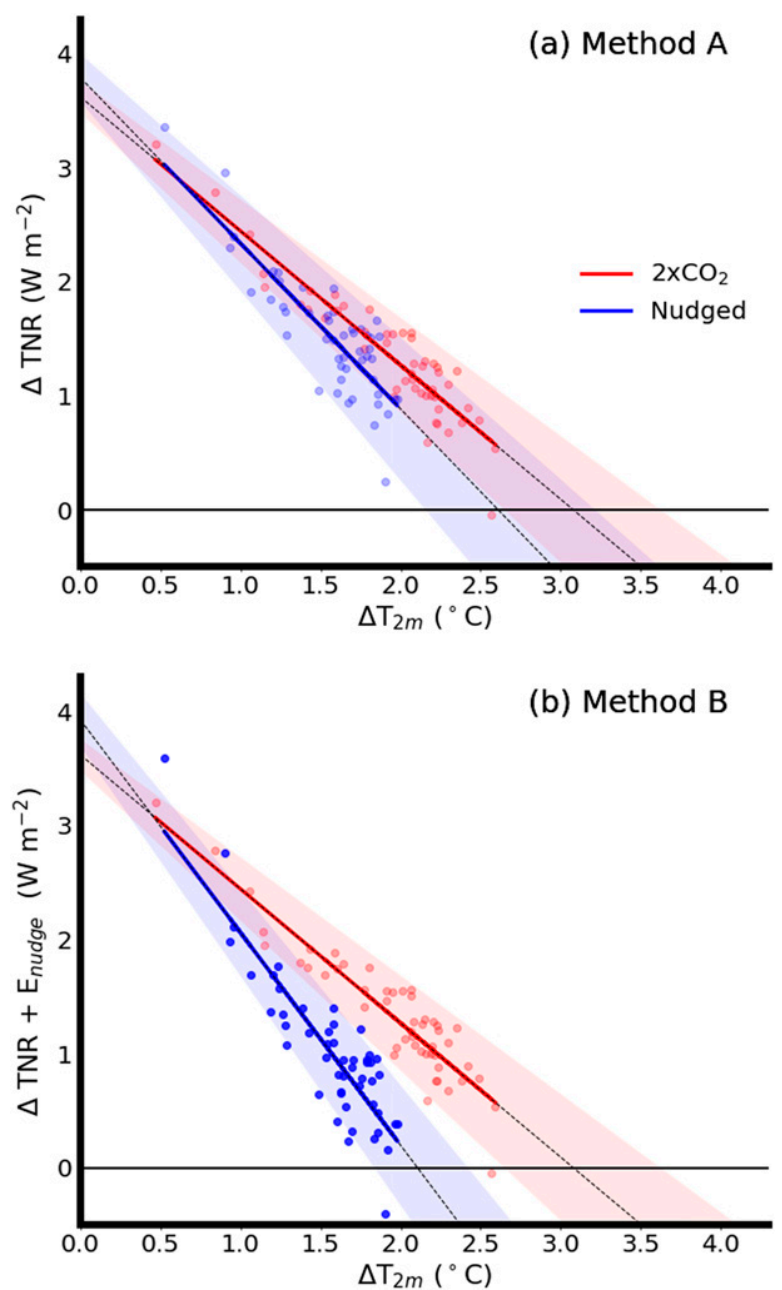

FIG. A2. Regression lines to obtain the climate feedback estimate as by Gregory et al. (2004). Simulations: nudged (blue) and $2 \mathrm{xCO}_{2}$ (red). The scatter shows annual averages of fifty years. The line shows the linear regression through these points. The contours show the band of error from the slope error and the intercept error. Corresponding slope statistics are shown in Table 2. (a) Regression as in method $\mathrm{A}$ where the top radiation change at the top of the atmosphere difference $\Delta \mathrm{TNR}$ with the control is regressed against the global mean 2-m temperature change $\Delta T_{2 \mathrm{~m}}$. (b) Regression as in method B, where the sum of the nudge energy $E_{\text {nudge }}$ and $\Delta \mathrm{TNR}$ is regressed against $\Delta T_{2 \mathrm{~m}}$.

(A), resulting in a sea ice feedback of $0.28 \pm$ $0.15 \mathrm{~W} \mathrm{~m}^{-2} \mathrm{~K}^{-1}$. However, the total net energy entering the climate system in the nudged and the $2 \mathrm{xCO}_{2}$ simulation is not equal. The nudging protocol affects the net energy entering the system, as visualized in (Fig. A1). Therefore, we present an alternative method (B) to evaluate the climate feedback that takes into account all energy used in the nudging protocol $E_{\text {nudge }}$ [see Eq. (3)] as an external forcing of the climate system. We define $\Delta T_{\text {eq }}$ as the global mean temperature change that occurred when the sum of $E_{\text {nudge }}$ and $\Delta T_{2 \mathrm{~m}}$ is zero. Hence, 
TABLE A1. Slope estimation using the method of Gregory et al. (2004). The uncertainties of the slope and the intercept obtained from least squares fit, where the line is fit by minimizing the residuals only in $y$.

\begin{tabular}{llcccrr}
\hline \hline Simulation & \multicolumn{1}{c}{ What is regressed } & Slope $\lambda_{f}$ & Intercept $\Delta Q$ & $\Delta T_{\text {eq }}$ & $r$ & $p$ \\
\hline $2 \mathrm{xCO}_{2}$ & $\Delta \mathrm{TNR}$ vs $\Delta T_{2 \mathrm{~m}}(\mathrm{~A})$ & $-1.17 \pm 0.07$ & $3.62 \pm 0.14$ & 3.08 & 0.93 & $8.19 \times 10^{-22}$ \\
Nudged & $\Delta \mathrm{TNR}$ vs $\Delta T_{2 \mathrm{~m}}(\mathrm{~A})$ & $-1.45 \pm 0.13$ & $3.79 \pm 0.21$ & 2.61 & 0.85 & $8.37 \times 10^{-15}$ \\
Nudged & $\left(\Delta \mathrm{TNR}+E_{\text {nudge }}\right)$ vs $\Delta T_{2 \mathrm{~m}}(\mathrm{~B})$ & $-1.86 \pm 0.15$ & $3.92 \pm 0.23$ & 2.11 & 0.88 & $5.16 \times 10^{-17}$ \\
\hline
\end{tabular}

we regress the sum of $E_{\text {nudge }}$ and TNR against $\Delta T_{2 \mathrm{~m}}$ to obtain the climate feedback using method B (Fig. A2b), which yields $\lambda_{\text {ice, } \mathrm{B}}=0.68 \pm 0.16 \mathrm{~W} \mathrm{~m}^{-2} \mathrm{~K}^{-1}$ (Tables A1 and A2). If, in theory, the experiment had been continued for several hundreds of years, the TNR would tend to be larger than zero, because the net energy sink due to nudging would be balanced by TNR. Thus, this way of estimating the feedback seems a valid alternative because the Gregory feedback framework assumes that the final equilibrium response to any perturbation is independent of the type of perturbation. We however do prefer the standard Gregory method (A) for several reasons:

First, the standard Gregory method result is comparable to previous studies. Second, the Gregory method is typically used for experiments with instantaneous, not time-varying, perturbations. In our case, applying the nudging energy provides a very large positive heat source in the first time step (Fig. 4b). Strictly speaking, the temporal variation in the nudging energy therefore does not adhere to the exponential curve required to make use of the Gregory method. This initialization problem can therefore influence the $\lambda_{\text {ice, B }}$ estimate. Finally, $E_{\text {nudge }}$ is not independent from $\Delta T_{2 \mathrm{~m}}$. Our experiment aims to eliminate the effects of surface temperature increase on the net energy entering the system, which depend solely on the variable sea ice cover for their mechanism.

A more fundamental problem with method $B$ is that in the nudged experiment, the net energy entering the system is not only depending on TNR, but also on $E_{\text {nudge }}$ The amount of energy $E_{\text {nudge }}$ required to maintain the sea ice cover is not independent of the temperature increase that has occurred relative to the control $\left(\Delta T_{2 \mathrm{~m}}\right)$. Thus as $\Delta T_{2 \mathrm{~m}}$ increases when the climate warms, the net energy entering the system decreases. This decrease is partly caused by changes in TNR (as diagnosed in method A) - but a larger part is related to changes in $E_{\text {nudge }}$ Hence $E_{\text {nudge }}$ imposes a negative feedback in the climate system, which is not directly related to sea ice processes. The artificial negative feedback imposed by $E_{\text {nudge }}$ is a product of the experimental design. Taking $E_{\text {nudge }}$ explicitly into account might result in diagnosing the feedback strength including this artificial effect, while we aim to diagnose the physical feedbacks related to sea ice.
The act of nudging leads to a higher $\Delta T_{2 \mathrm{~m}}$ once equilibrium is reached, and this fact could be a reason to use method B. However, it is not clear if nudging leads to a higher $\Delta T_{2 \mathrm{~m}}$ instantaneously and further, it is not clear that $E_{\text {nudge }}$ alters the relation between $\Delta T_{2 \mathrm{~m}}$ and TNR directly, or whether it affects the final TNR simply by inducing a cooler $\Delta T_{2 \mathrm{~m}}$. Note that in areas where the nudging fails to restore the control sea ice cover, the nudging alters the SST, which leads to a different LW out. In this way, the nudging alters the TNR in a way unrelated to the desired sea ice cover.

Simply combining $E_{\text {nudge }}$ and $\Delta \mathrm{TNR}$ and assuming a linear response in $\Delta T_{2 \mathrm{~m}}$ (method B) is likely a too simplistic approximation to deal with $E_{\text {nudge }}$ Subtracting all energy associated with nudging, $E_{\text {nudge }}$, from TNR in making the $\lambda_{\text {ice }}$ estimate is equivalent to assuming that the act of nudging increases the function $\operatorname{TNR}\left(T_{2 \mathrm{~m}}\right)$ by $E_{\text {nudge }}\left(T_{2 \mathrm{~m}}\right)$, which is likely an oversimplification of the system. The experimental design does not allow a deeper analysis to isolate the effect of nudging on the relationship between $\Delta T_{2 \mathrm{~m}}$ and $\triangle \mathrm{TNR}$ itself.

The upper limit of our $\lambda_{\text {ice }}$ estimate is influenced by the magnitude of the heat sink $E_{\text {nudge }}$. This is because $\lambda_{\text {ice, } \mathrm{B}}$ is more susceptible to the assumptions and choices applied in the nudging procedure, as $E_{\text {nudge }}$ strongly depends on initial ocean fields, the restoring time scale, etc. In other words, this is a limitation inherent to our method, and therefore the upper limit value of 0.68 is likely an overestimation of the sea ice feedback strength. For these reasons, we conclude that adding $E_{\text {nudge }}$ does not improve our understanding of the Arctic sea ice feedback. Therefore, we interpret the result of method

TABLE A2. Climate feedbacks according to method A and B. The feedback related to Arctic sea ice is computed as $\lambda_{f}^{2 \times \mathrm{CO}_{2}}-\lambda_{f}^{\text {nudged }}$. Here, $\lambda_{f}^{2 \mathrm{xCO}_{2}}=-1.17 \pm 0.07$. The reported standard deviation of $\lambda_{\text {ice }}$ is the combination of the standard slope errors of $\lambda_{f}^{2 \mathrm{xCO}_{2}}$ and $\lambda_{f}^{\text {nudged }}$.

\begin{tabular}{ccc}
\hline \hline Method to calculate & $\lambda_{f}^{\text {nudged }}$ & $\lambda_{f}^{2 \mathrm{xCO}_{2}}-\lambda_{f}^{\text {nudged }}$ \\
\hline$\lambda_{f_{\mathrm{A}}}^{\text {nudged }}=-\frac{\Delta \mathrm{TNR}}{\Delta T_{\text {eq }}}$ & $-1.45 \pm 0.13$ & $\lambda_{\text {ice }_{\mathrm{A}}}=0.28 \pm 0.15$ \\
$\lambda_{f_{\mathrm{B}}}^{\text {nudged }}=-\frac{\Delta\left(\mathrm{TNR}+E_{\text {nudge }}\right)}{\Delta T_{\text {eq }}}$ & $-1.86 \pm 0.15$ & $\lambda_{\text {ice }_{\mathrm{B}}}=0.68 \pm 0.16$
\end{tabular}


$\mathrm{B}$ as $\lambda_{\text {ice }}$ including the maximum effect our nudging method has on our feedback estimate.

\section{REFERENCES}

Andry, O., R. Bintanja, and W. Hazeleger, 2017: Time-dependent variations in the Arctic's surface albedo feedback and the link to seasonality in sea ice. J. Climate, 30, 393-410, https://doi.org/ 10.1175/JCLI-D-15-0849.1.

Årthun, M., T. Eldevik, L. H. Smedsrud, Ø. Skagseth, and R. Ingvaldsen, 2012: Quantifying the influence of Atlantic heat on Barents Sea ice variability and retreat. J. Climate, 25, 47364743, https://doi.org/10.1175/JCLI-D-11-00466.1.

Bhatt, U. S., and Coauthors, 2014: Implications of Arctic Sea ice decline for the Earth system. Annu. Rev. Environ. Resour., 39, 57-89, https://doi.org/10.1146/annurev-environ-122012-094357.

Bintanja, R., and J. Oerlemans, 1995: The influence of the albedotemperature feed-back on climate sensitivity. Ann. Glaciol., 21, 353-360, https://doi.org/10.1017/S0260305500016062.

—_, and F. M. Selten, 2014: Future increases in Arctic precipitation linked to local evaporation and sea-ice retreat. Nature, 509, 479-482, https://doi.org/10.1038/nature13259.

Block, K., and T. Mauritsen, 2013: Forcing and feedback in the MPI-ESM-LR coupled model under abruptly quadrupled $\mathrm{CO}_{2}$. J. Adv. Model. Earth Syst., 5, 676-691, https://doi.org/ 10.1002/jame.20041.

Boisvert, L. N., T. Markus, and T. Vihma, 2013: Moisture flux changes and trends for the entire Arctic in 2003-2011 derived from EOS Aqua data. J. Geophys. Res. Oceans, 118, 58295843, https://doi.org/10.1002/jgrc.20414.

Bouillon, S., M. A. M. Maqueda, V. Legat, and T. Fichefet, 2009: An elastic-viscous-plastic sea ice model formulated on Arakawa B and C grids. Ocean Modell., 27, 174-184, https://doi.org/ 10.1016/j.ocemod.2009.01.004.

Caldeira, K., and I. Cvijanovic, 2014: Estimating the contribution of sea ice response to climate sensitivity in a climate model. J. Climate, 27, 8597-8607, https://doi.org/10.1175/JCLI-D-1400042.1.

Collins, M., and Coauthors, 2013: Long-term climate change: Projections, commitments and irreversibility. Climate Change 2013: The Physical Science Basis, T. F. Stocker et al., Eds., Cambridge University Press, 1029-1136.

Deser, C., R. A. Tomas, and L. Sun, 2015: The role of oceanatmosphere coupling in the zonal-mean atmospheric response to Arctic sea ice loss. J. Climate, 28, 2168-2186, https://doi.org/ 10.1175/JCLI-D-14-00325.1.

Fichefet, T., and M. Maqueda, 1997: Sensitivity of a global sea ice model to the treatment of ice thermodynamics and dynamics. J. Geophys. Res. Oceans, 102, 12 609-12 646, https://doi.org/ 10.1029/97JC00480.

Flato, G. M., 2004: Sea-ice and its response to $\mathrm{CO}_{2}$ forcing as simulated by global climate models. Climate Dyn., 23, 229241, https://doi.org/10.1007/s00382-004-0436-7.

Goosse, H., P.-Y. Barriat, M.-F. Loutre, and V. Zunz, 2010: The response of the climate system to a perturbation. Introduction to Climate Dynamics and Climate Modelling, Cambridge University Press, 87-108.

Graversen, R. G., and M. Wang, 2009: Polar amplification in a coupled climate model with locked albedo. Climate Dyn., 33, 629-643, https://doi.org/10.1007/s00382-009-0535-6.

_- P. L. Langen, and T. Mauritsen, 2014: Polar amplification in CCSM4: Contributions from the lapse rate and surface albedo feedbacks. J. Climate, 27, 4433-4450, https://doi.org/10.1175/ JCLI-D-13-00551.1.

Gregory, J., and Coauthors, 2004: A new method for diagnosing radiative forcing and climate sensitivity. Geophys. Res. Lett., 31, L03205, https://doi.org/10.1029/2003GL018747.

Hazeleger, W., and Coauthors, 2012: EC-Earth v2. 2: Description and validation of a new seamless Earth system prediction model. Climate Dyn., 39, 2611-2629, https://doi.org/10.1007/ s00382-011-1228-5.

Holland, M. M., and C. M. Bitz, 2003: Polar amplification of climate change in coupled models. Climate Dyn., 21, 221-232, https:// doi.org/10.1007/s00382-003-0332-6.

Ingram, W. J., C. A. Wilson, and J. F. B. Mitchell, 1989: Modeling climate change: An assessment of sea ice and surface albedo feedbacks. J. Geophys. Res., 94, 8609-8622, https://doi.org/ 10.1029/JD094iD06p08609.

Koyama, T., J. Stroeve, J. Cassano, and A. Crawford, 2017: Sea ice loss and Arctic cyclone activity from 1979 to 2014. J. Climate, 30, 4735-4754, https://doi.org/10.1175/JCLI-D-16-0542.1.

Li, D., R. Zhang, and T. R. Knutson, 2017: On the discrepancy between observed and CMIP5 multi-model simulated Barents Sea winter sea ice decline. Nat. Commun., 8, 14991, https://doi.org/ 10.1038/ncomms14991.

Madec, G., and Coauthors, 2008: NEMO ocean engine. IPSL Note du Pôle de Modelisation 27, 209 pp.

Massonnet, F., T. Fichefet, H. Goosse, M. Vancoppenolle, P. Mathiot, and C. König Beatty, 2011: On the influence of model physics on simulations of Arctic and Antarctic sea ice. Cryosphere, $\mathbf{5}$, 687-699, https://doi.org/10.5194/tc-5-687-2011.

Mauritsen, T., R. G. Graversen, D. Klocke, P. L. Langen, B. Stevens, and L. Tomassini, 2013: Climate feedback efficiency and synergy. Climate Dyn., 41, 2539-2554, https://doi.org/ 10.1007/s00382-013-1808-7.

Oudar, T., E. Sanchez-Gomez, F. Chauvin, J. Cattiaux, L. Terray, and C. Cassou, 2017: Respective roles of direct GHG radiative forcing and induced Arctic sea ice loss on the Northern Hemisphere atmospheric circulation. Climate Dyn., 49, 3693 3713, https://doi.org/10.1007/s00382-017-3541-0.

Overland, J. E., and Coauthors, 2016: Nonlinear response of midlatitude weather to the changing Arctic. Nat. Climate Change, 6, 992-999, https://doi.org/10.1038/nclimate3121.

Rind, D., R. Healy, C. Parkinson, and D. Martinson, 1995: The role of sea ice in $2 \mathrm{xCO}_{2}$ climate model sensitivity. Part I: The total influence of sea ice thickness and extent. J. Climate, $\mathbf{8}$, https:// doi.org/10.1175/1520-0442(1995)008<0449:TROSII >2.0.CO;2.

,,$-- \ldots$, and —_ 1997: The role of sea ice in $2 \mathrm{xCO}_{2}$ climate model sensitivity. Part II: Hemispheric dependencies. Geophys. Res. Lett., 24, 1491-1494, https://doi.org/10.1029/97GL01433.

Schweiger, A., R. Lindsay, J. Zhang, M. Steele, H. Stern, and R. Kwok, 2011: Uncertainty in modeled Arctic sea ice volume. J. Geophys. Res., 116, C00D06, https://doi.org/10.1029/2011JC007084.

Screen, J. A., and I. Simmonds, 2010: The central role of diminishing sea ice in recent Arctic temperature amplification. Nature, 464, 1334-1337, https://doi.org/10.1038/nature09051. , and Coauthors, 2018: Consistency and discrepancy in the atmospheric response to Arctic sea-ice loss across climate models. Nat. Geosci., 11, 155-163, https://doi.org/10.1038/s41561-018-0059-y.

Serreze, M. C., and R. G. Barry, 2011: Processes and impacts of Arctic amplification: A research synthesis. Global Planet. Change, 77, 85-96, https://doi.org/10.1016/j.gloplacha.2011.03.004.

Smedsrud, L. H., and Coauthors, 2013: The role of the Barents Sea in the Arctic climate system. Rev. Geophys., 51, 415-449, https://doi.org/10.1002/rog.20017. 
Snape, T. J., and P. M. Forster, 2014: Decline of Arctic sea ice: Evaluation and weighting of CMIP5 projections. J. Geophys. Res., 119, 546-554, https://doi.org/10.1002/ 2013JD020593.

Soden, B. J., I. M. Held, R. Colman, K. M. Shell, J. T. Kiehl, and C. A. Shields, 2008: Quantifying climate feedbacks using radiative kernels. J. Climate, 21, 3504-3520, https://doi.org/ 10.1175/2007JCLI2110.1.

Sterl, A., and Coauthors, 2012: A look at the ocean in the EC-Earth climate model. Climate Dyn., 39, 2631-2657, https://doi.org/ 10.1007/s00382-011-1239-2.

Thomas, K., 2014: Linkages between Arctic Warming and MidLatitude Weather Patterns: Summary of a Workshop. National Academies Press, 85 pp., https://doi.org/10.17226/18727.

Tietsche, S., D. Notz, J. H. Jungclaus, and J. Marotzke, 2011: Recovery mechanisms of Arctic summer sea ice. Geophys. Res. Lett., 38, L02707, https://doi.org/10.1029/2010GL045698.

Tomas, R. A., C. Deser, and L. Sun, 2016: The role of ocean heat transport in the global climate response to projected Arctic sea ice loss. J. Climate, 29, 6841-6859, https://doi.org/10.1175/ JCLI-D-15-0651.1.

van der Linden, E., 2016: Arctic climate change and decadal variability. Ph.D. thesis, Wageningen University, $195 \mathrm{pp}$.

, R. Bintanja, W. Hazeleger, and C. Katsman, 2014: The role of the mean state of Arctic sea ice on near-surface temperature trends. J. Climate, 27, 2819-2841, https://doi.org/10.1175/ JCLI-D-12-00617.1.

,-- , and — 2017: Arctic decadal variability in a warming world. J. Geophys. Res. Atmos., 122, 5677-5696, https:// doi.org/10.1002/2016JD026058.

Vial, J., J.-L. Dufresne, and S. Bony, 2013: On the interpretation of inter-model spread in CMIP5 climate sensitivity estimates. Climate Dyn., 41, 3339-3362, https://doi.org/10.1007/ s00382-013-1725-9.

Wang, K., C. Deser, L. Sun, and R. A. Tomas, 2018: Fast response of the tropics to an abrupt loss of Arctic sea ice via ocean dynamics. Geophys. Res. Lett., 45, 4264-4272, https://doi.org/ 10.1029/2018GL077325. 